Original Research

\title{
Professional Baseball Player Type and Geographic Region of Origin Impacts Shoulder External and Internal Rotation Strength
}

\author{
Lori A. Michener, PhD, PT, ATC ${ }^{1}$ a , Adam J. Barrack, MS, CSCS ${ }^{1}$, Bernard Y. Liebeskind', Ryan J. Zerega, BSE, MS², \\ Jonathan C. Sum, PT, DPT ${ }^{1}$, Ryan L. Crotin, PhD, CSCS ${ }^{3}$, Hillary A. Plummer, PhD, ATC \\ ${ }^{1}$ Division of Biokinesiology and Physical Therapy, University of Southern California, ${ }^{2}$ Atrium Health Musculoskeletal Institute, ${ }^{3}$ Louisiana Tech \\ University; Sports Performance Research Institute New Zealand Auckland University of Technology \\ Keywords: overhead athlete, rotator cuff strength, pitching, shoulder \\ https://doi.org/10.26603/001c.25237
}

\section{International Journal of Sports Physical Therapy}

Vol. 16, Issue 4, 2021

\section{Background}

Shoulder strength deficits are implicated in arm injuries and performance deficits in baseball players.

\section{Purpose}

To characterize shoulder external (ER) and internal (IR) rotation strength in professional baseball players, and compare strength across player type (pitchers, position players) and geographic origin (North America, Latin America).

\section{Study Design}

Cross-sectional.

\section{Methods}

Minor league professional baseball players from North America and Latin America $(n=242$; age $=22.4 \pm 2.3$ years; $n=135$ pitchers and $n=107$ position players; $n=162$ North American and $n=80$ Latin American players) volunteered at spring training. Bilateral shoulder IR and ER isometric strength was measured in sitting with the arm at the side using a handheld dynamometer stabilized on a wall via a specialized jig. Strength was normalized to body weight, and compared using t-tests between player type and geographic area of origin $(\mathrm{p}<0.05)$.

\section{Results}

Position players had greater strength in ER, IR and ER:IR (ER:0.7-2.7N/kg; IR:1.3-3.8N/kg; ER:IR ratio 0.36-1.22) compared to pitchers (ER:0.5-2.5N/kg; IR:0.6- 4.2N/kg; ER:IR ratio 0.44-1.16) on the throwing arm. North American pitchers had lower ER [MD $=-0.4$ (95\%CI:-0.7,-0.2);p=0.002] and IR [MD= -0.2 (95\%CI:-0.4,-0.1);p=0.006] than Latin American pitchers on the throwing arm. There were no differences between geographic groups for position players.

\section{Discussion/Conclusions}

Player position and geographic origin influence shoulder rotational strength values in professional baseball players. Position players have $14-20 \%$ higher ER and IR isometric

\footnotetext{
a Corresponding author:

Lori Michener, PhD, PT, ATC, FAPTA

Professor; Director, Clinical Outcomes and Research

Director, COOR Lab https://sites.usc.edu/coorlab/

Division of Biokinesiology and Physical Therapy

University of Southern California

1540 E. Alcazar Street, CHP 155 | Los Angeles, CA 90089

lmichene@usc.edu;

323-442-0247 | Fax: 323.442.1515

Twitter: @LoriMichener
} 
strength than pitchers. Moreover, Latin American pitchers exhibited 11.8\% greater ER strength and $16.7 \%$ greater IR strength as compared to North American pitchers.

Normative values can be used to determine player deficits, declines in performance, and targets for return to play after injury.

\section{Level of Evidence}

Level II

\section{INTRODUCTION}

Baseball continues to be a popular sport played worldwide. Upper extremity injuries are prevalent, accounting for more than $54 \%$ of all days spent on the disabled list for professional baseball players. ${ }^{1}$ Injury risk is related to the position played, with pitchers reporting the highest number of upper extremity injuries. ${ }^{1,2}$ Shoulder girdle muscles provide stabilization and control of the glenohumeral joint during acceleration, deceleration, and follow through phases of throwing. Specific deficits in strength of the muscles of shoulder external rotation (ER) and internal rotation (IR), and the ER:IR ratio have been linked to upper extremity injury 3,4 and impact on performance ${ }^{5}$ in baseball. Normative data on shoulder rotational strength profiles are needed to identify deficits, and enable return to sport decision-making.

The majority of baseball-related literature has focused on pitchers. ${ }^{6}$ Given the variability in throwing mechanics and demands between position players and pitchers, rotational shoulder strength profiles may be different. Studies are limited that describe shoulder ER and IR strength in non-injured professional baseball pitchers and position players using isokinetic and isometric methods. ${ }^{4,7-9}$ Unfortunately, isokinetic equipment is expensive, and not readily available for all baseball organizations. ${ }^{7,9}$ Hand held dynamometers (HHD) are less expensive, clinically available, and are easy use to test strength. Prior studies using a HHD have not consistently provided adequate stabilization, contributing to high variability in the strength measures. ${ }^{4,8}$

Normative strength profiles may also be impacted by demographic and cultural factors. Approximately $40 \%$ of professional baseball players are born outside of the United States. ${ }^{10,11}$ Practice frequency and duration, ${ }^{6,12}$ season and offseason length, ${ }^{13}$ strength and conditioning practices, and health services practices vary between geographic regions. Two prior studies found that baseball players from the Latin America had greater humeral retrotorsion and different functional shoulder movement patterns than those from the United States. ${ }^{14,15}$ Cultural factors of a geographic region may define the parameters of sport training, and thus influence performance, movement, and strength patterns.

Currently, it is unclear if shoulder rotational strength profiles are influenced by position played and geographic region of origin. The purpose of this study was to describe shoulder ER, IR, and ER:IR strength values in Minor League Baseball (MiLB) professional players, and to compare strength values across geographic origin (North American versus Latin American) players and between player type (pitcher versus position player).

\section{METHODS}

A cohort study design was used to characterize the shoulder rotational strength profiles for professional MiLB baseball players. Player type categorized players as position player or pitcher to determine the differences of player type on strength. Players who listed pitching as a secondary position, were classified as a pitcher if they pitched at least 10 , multiple-inning games in the previous season. Geographic area of origin was defined by two groups; North America and Latin America. The North American group consisted of athletes from the United States and Canada. The Latin American group consisted of athletes from the Dominican Republic, Puerto Rico, Venezuela, Colombia, Cuba, Mexico, and Panama.

\section{SUBJECTS}

Data were collected on 242 professional MiLB baseball players $(n=135$ pitchers and $n=107$ position players) during each year of three years of spring training physical examinations (2016-2018). If a player was tested more than once over the three years, only the most recent year was used for data analysis. Inclusion criteria was: on a team roster for a MiLB team at pre-season. Exclusion criteria were 1) not cleared to participate in baseball activities, 2) current report of pain in the shoulder or elbow, 3) currently receiving treatment for a shoulder or elbow injury, and 4) from a country outside of Latin and North Americas. Demographics grouped by position and geographic region are described in Table 1. Years of MiLB experience was defined as the number of years from the year drafted. This study was approved by the Institutional Review Board (IRB) at the University of Southern California, and the subjects signed an informed consent to participate in this study.

\section{PROCEDURES}

Height and weight were measured using a tape measure and scale respectively. Shoulder strength was measured on both their dominant and non-dominant arms. Shoulder ER and IR strength were measured in a seated position, with the arm placed by the side with a towel roll under the axilla, and the elbow flexed to $90^{\circ}$ (Figure 1). A handheld dynamometer (Hoggan Scientific, Lafayette, IN) was attached to a stabilizing device that was novel for this investigation (see Fig-

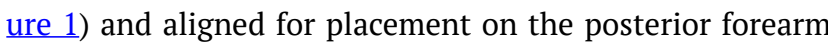
just proximal to the ulnar styloid process for ER strength. For IR strength, the handheld dynamometer was placed on the anterior forearm just proximal to the wrist. Players performed two maximal effort isometric contractions with the instructions to "push as hard as possible for five seconds". One minute of rest was given between each trial. Strength 
values were normalized to body weight $(\mathrm{N} / \mathrm{kg}){ }^{4,7-9,16}$ The average of two trials for shoulder ER and IR, and ER to IR ratio (ER/IR) was used for data analysis. 
Table 1. Descriptive data by player type and geographic region; Mean, standard deviation (SD), and interquartile range.

\begin{tabular}{|c|c|c|c|c|c|c|c|c|c|}
\hline & \multirow{2}{*}{$\begin{array}{l}\text { Group } \\
\text { Size } \\
N\end{array}$} & \multicolumn{2}{|c|}{$\begin{array}{l}\text { Age } \\
\text { (yrs) }\end{array}$} & \multicolumn{2}{|c|}{$\begin{array}{l}\text { Height } \\
\text { (cm) }\end{array}$} & \multicolumn{2}{|c|}{$\begin{array}{l}\text { Weight } \\
\text { (kg) }\end{array}$} & \multicolumn{2}{|c|}{$\begin{array}{l}\text { MiLB Experience } \\
\text { (yrs) }\end{array}$} \\
\hline & & Mean $\pm S D$ & $\begin{array}{l}\text { 25th, } \\
\text { 75th }\end{array}$ & Mean $\pm S D$ & 25th, 75th & Mean $\pm S D$ & 25th, 75th & Mean $\pm S D$ & $\begin{array}{l}25 \text { th, } \\
75 \text { th }\end{array}$ \\
\hline \multicolumn{10}{|l|}{ All Athletes } \\
\hline All Players & 242 & $22.4 \pm 2.3$ & $21.0,24.0$ & $185.9 \pm 6.7$ & $\begin{array}{l}182.9 \\
190.5\end{array}$ & $89.8 \pm 11.0$ & $81.8,97.9$ & $2.7 \pm 1.8$ & $1.0,4.0$ \\
\hline Pitchers & 135 & $22.6 \pm 2.4$ & $21.0,24.0$ & $188.6 \pm 6.3^{a}$ & $\begin{array}{l}182.9 \\
193.0\end{array}$ & $\begin{array}{l}92.4 \pm \\
11.2^{a}\end{array}$ & $\begin{array}{l}84.1 \\
100.0\end{array}$ & $2.7 \pm 1.9$ & $1.0,4.0$ \\
\hline $\begin{array}{l}\text { Position } \\
\text { Players }\end{array}$ & 107 & $22.2 \pm 2.2$ & $21.0,24.0$ & $182.4 \pm 5.4^{a}$ & $\begin{array}{l}177.8 \\
185.4\end{array}$ & $86.5 \pm 9.9^{a}$ & $79.5,92.7$ & $2.7 \pm 1.8$ & $1.0,4.0$ \\
\hline \multicolumn{10}{|l|}{ North America } \\
\hline All Players & 162 & $23.3 \pm 1.9^{c}$ & $22.0,24.0$ & $186.9 \pm 6.7^{c}$ & $\begin{array}{l}182.9 \\
190.5\end{array}$ & $92.6 \pm 9.2^{c}$ & $86.4,96.4$ & $2.3 \pm 1.7^{c}$ & $1.0,3.0$ \\
\hline Pitchers & 101 & $\begin{array}{l}23.4 \pm \\
1.9^{b}\end{array}$ & $23.0,24.0$ & $\begin{array}{c}189.3 \pm \\
6.4^{b d}\end{array}$ & $\begin{array}{l}185.4 \\
193.0\end{array}$ & $94.6 \pm 9.5^{b d}$ & $\begin{array}{l}88.6 \\
100.7\end{array}$ & $\begin{array}{l}2.5 \pm \\
1.8^{b d}\end{array}$ & $1.0,3.0$ \\
\hline $\begin{array}{l}\text { Position } \\
\text { Players }\end{array}$ & 61 & $\begin{array}{l}23.0^{ \pm} \\
1.8^{b}\end{array}$ & $22.0,24.0$ & $183.0 \pm 5.4^{d}$ & $\begin{array}{l}180.3 \\
185.4\end{array}$ & $89.1 \pm 7.7^{b d}$ & $84.1,94.3$ & $\begin{array}{l}1.9 \pm \\
1.2^{b d}\end{array}$ & $1.0,2.0$ \\
\hline \multicolumn{10}{|l|}{ Latin America } \\
\hline All Players & 80 & $20.8 \pm 2.3^{c}$ & $19.0,23.0$ & $183.7 \pm 6.0^{c}$ & $\begin{array}{l}180.3 \\
188.0\end{array}$ & $84.2 \pm 12.3^{c}$ & $76.4,90.5$ & $3.6 \pm 1.9^{c}$ & $2.0,5.0$ \\
\hline Pitchers & 34 & $\begin{array}{l}20.2 \pm \\
2.3^{b}\end{array}$ & $19.0,21.3$ & $\begin{array}{l}186.8 \pm \\
5.6^{b d}\end{array}$ & $\begin{array}{l}182.9 \\
191.1\end{array}$ & $\begin{array}{l}85.8^{ \pm} \\
13.4^{b}\end{array}$ & $76.4,91.7$ & $3.4 \pm 2.0^{b}$ & $2.0,5.0$ \\
\hline $\begin{array}{l}\text { Position } \\
\text { Players }\end{array}$ & 46 & $\begin{array}{l}21.2 \pm \\
2.2^{b}\end{array}$ & $20.0,23.0$ & $181.4 \pm 5.4^{d}$ & $\begin{array}{l}177.8 \\
185.4\end{array}$ & $\begin{array}{l}83.0 \pm \\
11.5^{b}\end{array}$ & $75.0,89.8$ & $3.7 \pm 1.8^{b}$ & $2.0,5.0$ \\
\hline $\begin{array}{l}\text { IiLB }=\text { Minor League Bas } \\
=\text { Significant differences } \\
=\text { Significant differences } \\
=\text { Significant differences } \\
=\text { Significant differences }\end{array}$ & $\begin{array}{l}\text { er vs. posi } \\
\text { America } \\
\text { America } \\
\text { eer vs. posi }\end{array}$ & $\begin{array}{l}\text { ssed by geograph } \\
\text { for pitchers; } \alpha \\
\text {, collapsed by atl } \\
n \text { a geographic ar }\end{array}$ & $\begin{array}{l}\text { as of origin; } \alpha= \\
\text { player type; } \alpha= \\
\text { origin; } \alpha=0.05\end{array}$ & & & & & & \\
\hline
\end{tabular}


Test-retest reliability for shoulder isometric strength measurements was established prior to data collection. Interclass correlation coefficient (ICC) 2-way mixed model, standard error of the measure (SEM), and minimal detectable change [MDC90\% = SEM X sqrt(2)] were calculated on $\mathrm{n}=10$ subjects prior to athlete testing. For IR strength, the ICC $(3,2)$ was 0.96 ; error metrics of the SEM of $0.09 \mathrm{~N} /$ $\mathrm{kg}$ and the MDC $90 \%$ of $0.20 \mathrm{~N} / \mathrm{kg}$. For ER strength, the ICC $(3,2)$ was 0.95 ; error metrics of the SEM of $0.08 \mathrm{~N} / \mathrm{kg}$ and the MDC $90 \%$ of $0.18 \mathrm{~N} / \mathrm{kg}$. For ER:IR, the ICC $(3,2)$ was 0.97 , error metrics of the SEM of $0.05 \mathrm{~N} / \mathrm{kg}$ and for the MDC $90 \%$ of $0.11 \mathrm{~N} / \mathrm{kg}$.

Sample size calculations were based on the MDC for ER, IR, and ER:IR; 80\% power and a significance level of 0.05 indicated the largest sample size of 90 athletes, with 45 per group for comparisons.

\section{STATISTICAL ANALYSES}

Shoulder strength mean and variance values were calculated for both the throwing and non-throwing arms. To determine if strength profiles of players from Latin American countries could be considered a homogenous group, a sensitivity analysis was performed on players from the Dominican Republic $(\mathrm{n}=40)$, Venezuela $(\mathrm{n}=26)$, Puerto Rico ( $=7$ ), Mexico $(n=2)$, Panama $(n=2)$, Cuba $(n=2)$, Colombia $(n=1)$. An ANOVA was performed between the groups with sufficient sample sizes (Dominican Republic and Venezuela), resulting in no differences in ER or IR strength values. For the five remaining countries with one to seven players, data was plotted by country. All values from these five countries were within the range for the group formed by the Dominican Republic and Venezuela, except for one Cuban player. For this Cuban player only the ER:IR on the non-dominant arm fell outside the range, but the measured ER and IR values for both arms were within the range of the larger group, so this player was included in the final data set. Data from the seven Latin American countries were considered a single, homogenous group for analysis.

Independent samples t-tests with equal variance were performed to identify differences in descriptive statistics (age, height, weight, age drafted, MiLB experience) between and within samples (pitcher vs. position player, North American vs. Latin American). Independent t-tests with equal variances were also used to test for differences in strength measures between Latin American and North American athletes (all athletes and comparisons of position players and pitchers), and between pitchers and position players (grouped by geographic area of origin and throwing arm). Statistical analyses were performed using IBM SPSS Statistics Version 24.0 (IBM, Armonk, NY) and R software (The R Foundation), alpha level of $\mathrm{p} \leqslant 0.05$.

\section{RESULTS}

\section{NORMATIVE DATA}

Table 1 presents the age, height, weight, and years of MiLB experience of the participants.

Normative data for athletes grouped by position and geographic area of origin are depicted in Figures $\underline{2}$ and $\underline{3}$. Pitchers throwing arm strength ranged for IR of 0.6 to $4.2 \mathrm{~N} / \mathrm{kg}$,

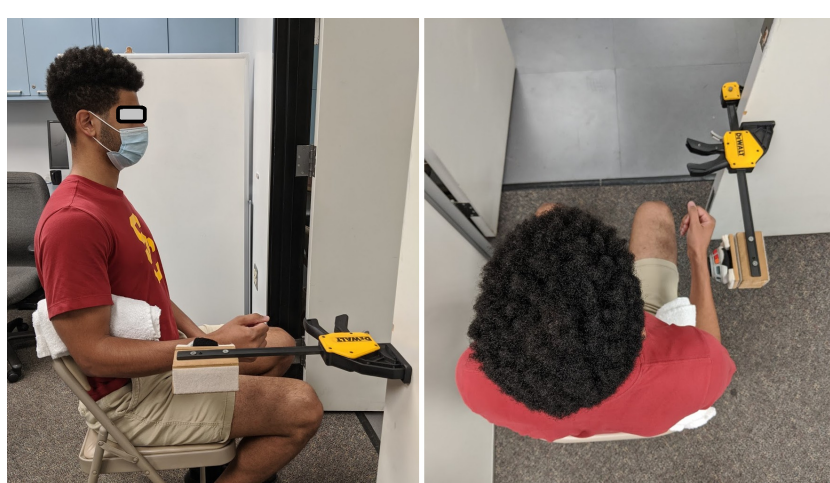

Figure 1A. Isometric strength testing with a handheld dynamometer in external rotation.
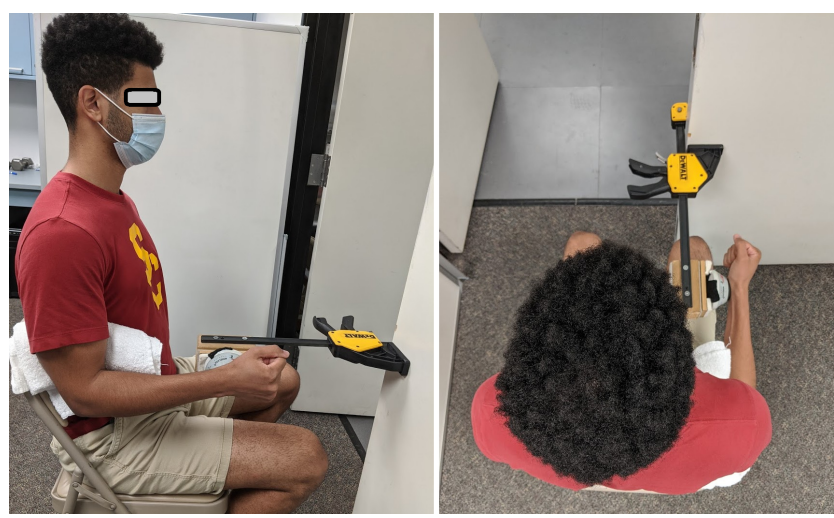

Figure 1B. Isometric strength testing with a handheld dynamometer in internal rotation.

ER of 0.5 to $2.5 \mathrm{~N} / \mathrm{kg}$, and an ER:IR ratio of 0.44 to 1.16 . Pitchers' non-throwing arm had strength ranges for IR of 0.6 to $3.7 \mathrm{~N} / \mathrm{kg}$, ER of 0.7 to $2.9 \mathrm{~N} / \mathrm{kg}$, and an ER:IR ratio ranging from 0.38 to 1.31 . Position players throwing arm strength range for IR of 1.3 to $3.8 \mathrm{~N} / \mathrm{kg}$, ER 0.7 to $2.7 \mathrm{~N} / \mathrm{kg}$, and ER:IR ratio range of 0.36 to 1.22 . For the non-throwing arm, position players strength for IR ranged from 1.1 to 4.1 $\mathrm{N} / \mathrm{kg}$, ER of 1.0 to $2.8 \mathrm{~N} / \mathrm{kg}$, and ER:IR of 0.47 to 1.44 .

\section{NORTH AMERICAN VERSUS LATIN AMERICAN PLAYERS}

Strength profiles by geographic region (Table 2) indicated Latin American athletes were stronger in ER and IR on the non-throwing and throwing arms ( $\mathrm{p}=0.005$ to $<0.001)$, collapsed across player type than North American athletes. There were no differences between geographic regions on ER:IR ratios on the throwing arm $(\mathrm{p}=0.898)$ and non-throwing $\operatorname{arm}(\mathrm{p}=0.824)$.

\section{PITCHERS VERSUS POSITION PLAYERS}

Strength profiles by player type (Table 3 ) indicated that pitchers were weaker in IR, ER, and ER:IR ratio when compared to position players for both the non-throwing arm and non-throwing arm ( $\mathrm{p}=0.0433$ to $<0.001)$, collapsed across geographic regions. 


\section{PLAYER TYPE BY POSITION AND GEOGRAPHIC REGION INTERACTION}

In North American players (Table 3), position players have higher ER and IR strength as compared to pitchers, for both the throwing arm $(\mathrm{p}<0.001)$ and non-throwing arm $(\mathrm{p}$ $<0.001, \mathrm{p}=0.002$ respectively). There were no differences between North American position players and pitchers in ER:IR strength ratio for the throwing $(p=0.358)$ and nonthrowing $(\mathrm{p}=0.102)$ arms.

Among Latin American athletes (Table 3), the ER:IR ratio was higher on the throwing arm in the position players versus pitchers $(p=0.020)$. Additionally, position players were stronger in ER $(p=0.002)$ and IR $(p=0.037)$ on the nonthrowing arm as compared to pitchers from Latin America. There were no significant differences $(p=0.119)$ between Latin American position players and pitchers in ER:IR strength ratio for the non-throwing arm.

Differences between geographic region by position indicate that North American pitchers were weaker in ER [MD= -0.4 (95\%CI: $-0.7,-0.2), \mathrm{p}=0.002]$ and IR [MD $=-0.2$ (95\%CI: $-0.4,-0.1), p=0.006]$ for the throwing arm when compared to their Latin American counterparts; all other strength measures were not different between geographic groups for pitchers. For position players, there were no differences between geographic groups.

\section{DISCUSSION}

Shoulder ER and IR muscles have a central role in glenohumeral stabilization, as well as arm acceleration and deceleration throughout the throwing motion. Shoulder ER and IR strength varied across player type and geographic region of origin in a cohort of 242 professional baseball players. Generally, position players were stronger than pitchers, and Latin American players tended to be stronger than their North American counterparts. Position players had higher ER and IR isometric strength than pitchers, respectively by $14-20 \%$ on their throwing arm and $15-20 \%$ on the non-throwing arm. Thus, the ER:IR ratio was higher by $5.5 \%$ and $6.9 \%$ on throwing and non-throwing arm respectively. Latin American players across both arms had 9.5 14.3\% higher isometric strength over North American players. Considering the intersection of player position and geographic region, Latin American pitchers exhibited 11.8\% greater ER strength and $16.7 \%$ greater IR strength as compared to North American pitchers. In the North American region only, position players were stronger in shoulder IR and ER and had a higher ER:IR ratio than pitchers. In Latin American player's throwing arm, only the ER:IR ratio was different between player type. In the non-throwing arm in Latin American position players had greater shoulder strength than pitchers.

Pitchers were generally weaker than position players. Specifically, position players were stronger in both the throwing and non-throwing arm ER, IR, and ER:IR ratio compared to pitchers.

This was a surprising result. A prior study ${ }^{7}$ did find no differences between player type for ER and IR strength, however they used isokinetic testing methods which differed from this current study. Pitchers commonly engage in
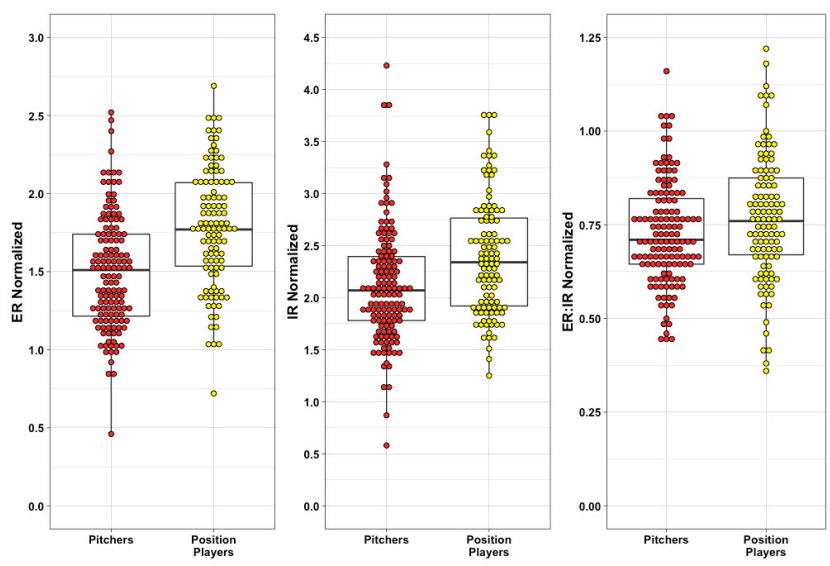

Figure 2. Individual player strength profiles for external rotation (ER), internal rotation (IR), and ER:IR shoulder strength by player type.
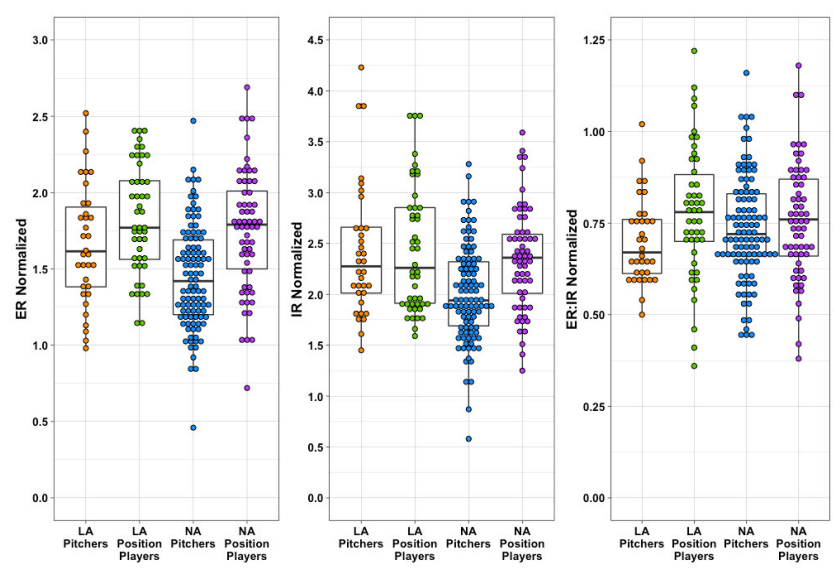

Figure 3. Individual player strength profiles for external rotation (ER), internal rotation (IR), and ER:IR shoulder strength by geographic region player type.

highly programmed specialized training, often termed "arm care”. The current study may indicate the arm care may be inadequate. Baseball players face different demands related to position, which may influence shoulder strength. Position players play every day whereas pitchers play once every four to five days. Alternatively, higher ball velocity and shoulder loads in pitchers may lead to fatigue or overuse, and thus weaker ER and IR muscles in the throwing arm in comparison to the position player cohort. Finally, player position may be dictated by shoulder strength; e.g, players who are stronger may select into a position player versus pitcher. These results may imply a change is needed in the training program for pitchers, with a focus on ER and IR strengthening.

Normative strength data derived from healthy players provide metrics that may be used to identify deficits that may be associated with injury or poor performance. For the throwing arm, pitchers had a mean range for IR strength of 0.6 to $4.2 \mathrm{~N} / \mathrm{kg}$ and ER of 0.5 to $2.5 \mathrm{~N} / \mathrm{kg}$, while position 
Table 2. External rotation (ER) and internal rotation (IR) strength profiles: by geographical region, collapsed across player type: mean, standard deviation (SD), and interquartile range; and mean differences (MD) for comparisons.

\begin{tabular}{|c|c|c|c|c|c|c|}
\hline & \multicolumn{2}{|c|}{$\begin{array}{l}\text { North America } \\
\qquad(\mathrm{N}=162)\end{array}$} & \multicolumn{2}{|c|}{$\begin{array}{l}\text { Latin America } \\
\qquad(N=80)\end{array}$} & \multicolumn{2}{|c|}{$\begin{array}{l}\text { North America vs. } \\
\text { Latin American }\end{array}$} \\
\hline & Mean $\pm S D$ & $25 \%, 75 \%$ & Mean $\pm S D$ & $25 \%, 75 \%$ & $\mathrm{MD}(95 \% \mathrm{Cl})$ & $P$ \\
\hline \multicolumn{7}{|l|}{ Throwing Arm } \\
\hline IR Strength (N/kg) & $2.1 \pm 0.5$ & $1.8,2.5$ & $2.4 \pm 0.6$ & $1.9,2.8$ & $-0.3(-0.4,-0.1)$ & $<0.001^{*}$ \\
\hline ER Strength (N/kg) & $1.6 \pm 0.4$ & $1.3,1.8$ & $1.8 \pm 0.4$ & $1.5,2.1$ & $-0.2(-0.3,-0.1)$ & $<0.001^{*}$ \\
\hline ER:IR Ratio & $0.74 \pm 0.15$ & $0.66,0.84$ & $0.75 \pm 0.16$ & $0.63,0.83$ & $-0.01(-0.04,0.04)$ & 0.898 \\
\hline \multicolumn{7}{|l|}{ Non-Throwing Arm } \\
\hline IR Strength (N/kg) & $2.1 \pm 0.5$ & $1.7,2.5$ & $2.3 \pm 0.6$ & $1.9,2.6$ & $-0.2(-0.4,0.1)$ & $0.005^{*}$ \\
\hline ER Strength (N/kg) & $1.5 \pm 0.4$ & $1.3,1.7$ & $1.7 \pm 0.4$ & $1.4,2.0$ & $-0.2(-0.3,0.1)$ & $0.004^{*}$ \\
\hline ER:IR Ratio & $0.76 \pm 0.17$ & $0.63,0.85$ & $0.75 \pm 0.17$ & $0.65,0.85$ & $0.01(-0.04,0.05)$ & 0.824 \\
\hline
\end{tabular}

* = Significant at $\alpha=0.05$

players IR strength ranged from 1.3 to $3.8 \mathrm{~N} / \mathrm{kg}$ and ER strength from 0.7 to $2.7 \mathrm{~N} / \mathrm{kg}$. Normalizing strength measures to body weight has a potential influence, as pitchers were heavier than position players. Previous studies in baseball players have assessed strength with the shoulder abducted at $0^{\circ}$ or $90^{\circ} .4,7-9,16$ Assessing strength at $90^{\circ}$ is a more functional position that replicates the position of the shoulder during throwing, but may yield different strength values than those at $0^{\circ}$ of abduction. Donatelli et al. ${ }^{8}$ reported values for HHD isometric ER:IR strength ratio at $90^{\circ}$ abduction of 0.83 for the throwing arm and 0.99 in the nonthrowing arm in professional baseball players. In the current study, pitchers had a 0.73 ratio for both arms. Position players had a higher ratios (0.77-0.78) in both arms.

A stable throwing shoulder is theorized to have an ER:IR of 1.9,17 An ER:IR less than 1 may contribute to upper extremity injury risk in professional baseball players, ${ }^{4}$ however examining the ratio alone does not provide direct information if the altered ratio is related to an ER or IR strength deficit. Deficits in ER and IR strength were reported in baseball players who have sustained an ulnar collateral ligament (UCL) injury. ${ }^{18}$ Calculating the ER:IR based on the reported means, the ER:IR for healthy pitchers was 0.70 and those with a UCL injury was lower at 0.66 . Tennis players with shoulder pain also have a lower ER:IR of 0.68 as compared to healthy players who had a ratio of 0.79 .19 An ER:IR ratio of 0.70 may be the threshold for an injury protective effect. This study presented an average value of 0.75 . Future research is needed to define specific ER:IR ratio thresholds for injury risk predictions.

Cultural differences in youth training methods may impact shoulder strength between regions between North American and Latin American players. Latin American athletes were stronger in ER and IR strength on both arms. North American players were heavier, which could be a factor as strength was normalized to body weight. The difference in IR and ER strength between groups exceeded the measurement error of the utilized measure (MDC90\%). There are major differences in access to training and coaching between geographical regions with sport performance centers readily available in North America. Regardless of differences in ER and IR strength between countries of origin, all players maintained a similar level of balance in ER:IR strength. Height was not used to normalize strength. A prior study ${ }^{16}$ indicated normalization by weight is the most effective method to reduce unwanted variability in shoulder strength measures. However, body weight alone does not account for differences in weight distribution or lean body mass.

It is common for Latin American players to join baseball academies affiliated with Major League Baseball Organizations at the age of 16 . Baseball training at that time for Latin American players focuses on skill development and sports specific strengthening, which is likely less than the regimen for their North American counterparts at the same age. Over the years, cultural changes in North America youth baseball have occurred and include year-round baseball, sports specialization, and showcases which increase playing intensity and volume. ${ }^{20}$ North American players were older in this study, but had slightly less professional baseball experience than Latin American players. North American players can be drafted immediately following high school or they can wait to play professional baseball three years after high school whereas many Latin American players begin their professional careers after high school or as early as 16 years of age. Participation in the off-season arm care, or playing intensity prior to spring training was not considered. Financial compensation and competitive pressure inside the milieu of professional baseball may have encouraged greater frequency and effort in training. These factors may account for the differences in observed strength.

The use of a standardized strength testing protocol with a stabilized HHD afforded low measurement error and reduced variability. Regarding limitations, information on the cultural upbringing, training access, and training regimens performed by players in this study was not available. Further research documenting training programs, training access and nutritional practices will strengthen the understanding of how exercise affects shoulder strength. All 
Table 3. External rotation (ER) and internal rotation (IR) shoulder strength by geographic region and player type mean, standard deviation (SD), and interquartile range; and mean differences (MD) for comparisons.

\begin{tabular}{|c|c|c|c|c|c|c|}
\hline & \multicolumn{2}{|c|}{ Position Players } & \multicolumn{2}{|c|}{ Pitchers } & \multicolumn{2}{|c|}{ Pitcher vs Position Player } \\
\hline & Mean $\pm S D$ & $25 \%, 75 \%$ & Mean $\pm S D$ & $25 \%, 75 \%$ & $\mathrm{MD}(95 \% \mathrm{Cl})$ & $\mathrm{P}$ \\
\hline All Athletes & \multicolumn{2}{|c|}{$N=107$} & \multicolumn{2}{|c|}{$N=135$} & & \\
\hline \multicolumn{7}{|l|}{ Throwing Arm } \\
\hline IR Strength (N/kg) & $2.4 \pm 0.6$ & $1.9,2.8$ & $2.1 \pm 0.6$ & $1.7,2.4$ & $0.3(0.1,0.4)$ & $<0.001^{*}$ \\
\hline ER Strength $(\mathrm{N} / \mathrm{kg})$ & $1.8 \pm 0.4$ & $1.5,2.1$ & $1.5 \pm 0.4$ & $1.2,1.7$ & $0.3(0.2,0.4)$ & $<0.001^{*}$ \\
\hline ER:IR Ratio & $0.77 \pm 0.17$ & $0.67,0.88$ & $0.73 \pm 0.14$ & $0.64,0.82$ & $0.04(0.00,0.08)$ & $0.043^{*}$ \\
\hline \multicolumn{7}{|l|}{ Non-Throwing Arm } \\
\hline IR Strength (N/kg) & $2.3 \pm 0.5$ & $2.0,2.7$ & $2.0 \pm 0.5$ & $1.7,2.3$ & $0.3(0.2,0.4)$ & $<0.001^{*}$ \\
\hline ER Strength (N/kg) & $1.8 \pm 0.4$ & $1.5,2.0$ & $1.5 \pm 0.3$ & $1.2,1,7$ & $0.3(0.2,0.4)$ & $<0.001^{*}$ \\
\hline ER:IR Ratio & $0.78 \pm 0.18$ & $0.66,0.86$ & $0.73 \pm 0.15$ & $0.61,0.84$ & $0.05(0.00,0.09)$ & $0.033^{*}$ \\
\hline North America & \multicolumn{2}{|c|}{$N=61$} & \multicolumn{2}{|c|}{$N=101$} & & \\
\hline \multicolumn{7}{|l|}{ Throwing Arm } \\
\hline IR Strength (N/kg) & $2.4 \pm 0.5$ & $2.0,2.6$ & $2.0 \pm 0.5$ & $1.7,2.3$ & $0.4(0.2,0.5)$ & $<0.001^{*}$ \\
\hline ER Strength (N/kg) & $1.8 \pm 0.4$ & $1.5,2.0$ & $1.5 \pm 0.3$ & $1.2,1.7$ & $0.3(0.2,0.4)$ & $<0.001^{*}$ \\
\hline ER:IR Ratio & $0.76 \pm 0.16$ & $0.66,0.87$ & $0.74 \pm 0.14$ & $0.66,0.83$ & $0.02(-0.03,0.07)$ & 0.358 \\
\hline \multicolumn{7}{|l|}{ Non-Throwing Arm } \\
\hline IR Strength (N/kg) & $2.3 \pm 0.5$ & $1.9,2.7$ & $2.0 \pm 0.5$ & $1.6,2.3$ & $0.3(0.1,0.4)$ & $0.002^{*}$ \\
\hline ER Strength (N/kg) & $1.7 \pm 0.4$ & $1.4,2.0$ & $1.4 \pm 0.3$ & $1.2,1.6$ & $0.3(0.2,0.4)$ & $<0.001^{*}$ \\
\hline ER:IR Ratio & $0.78 \pm 0.18$ & $0.68,0.87$ & $0.74 \pm 0.16$ & $0.61,0.84$ & $0.04(-0.01,0.10)$ & 0.102 \\
\hline Latin America & \multicolumn{2}{|c|}{$N=46$} & \multicolumn{2}{|c|}{$N=34$} & & \\
\hline \multicolumn{7}{|l|}{ Throwing Arm } \\
\hline IR Strength (N/kg) & $2.4 \pm 0.6$ & $1.9,2.9$ & $2.4 \pm 0.7$ & $2.0,2.7$ & $0.0(-0.3,0.3)$ & 0.855 \\
\hline ER Strength (N/kg) & $1.8 \pm 0.4$ & $1.5,2.1$ & $1.7 \pm 0.4$ & $1.4,1.9$ & $0.1(0.0,-0.3)$ & 0.058 \\
\hline ER:IR Ratio & $0.78 \pm 0.18$ & $0.69,0.90$ & $0.70 \pm 0.12$ & $0.61,0.77$ & $0.08(0.01,0.14)$ & $0.020^{*}$ \\
\hline \multicolumn{7}{|l|}{ Non-Throwing Arm } \\
\hline IR Strength (N/kg) & $2.4 \pm 0.5$ & $2.0,2.8$ & $2.2 \pm 0.5$ & $1.8,2.4$ & $0.2(0.0,0.5)$ & $0.037^{*}$ \\
\hline ER Strength (N/kg) & $1.8 \pm 0.4$ & $1.5,2.1$ & $1.5 \pm 0.4$ & $1.2,1.7$ & $0.3(0.1,0.5)$ & $0.002^{*}$ \\
\hline ER:IR Ratio & $0.78 \pm 0.18$ & $0.65,0.85$ & $0.72 \pm 0.14$ & $0.64,0.85$ & $0.06(-0.02,0.13)$ & 0.119 \\
\hline
\end{tabular}

* = Significant comparison within group at $\alpha=0.05$

position players were collapsed into a single group, as there were not enough subjects to do a subgroup analysis for each player type. It is possible that certain position players have different strength profiles due to the specific demands of each position.

\section{CONCLUSIONS}

Baseball continues to draw a high level of international participation, yet arm injuries remain common. The results of the current study indicate that player position and geographic region of origin have an impact on shoulder rotational strength values in professional baseball players. Position players from both regions have higher shoulder rotational strength values than pitchers. Moreover, Latin American pitchers have stronger ER and IR as compared to their North American counterparts. Normative values of shoulder rotational strength for Latin and North American baseball players can be leveraged to identify player deficits, development of performance training programs, and inform assessment of player performance.

\section{DISCLOSURE OF FUNDING}

Major League Baseball Research Grant: Risk Factors Associated with Upper Extremity Injuries in Baseball.

\section{CONFLICTS OF INTEREST}

The authors report no conflicts of interest associated with this manuscript.

Submitted: November 24, 2020 CDT, Accepted: March 18, 2021 CDT 
This is an open-access article distributed under the terms of the Creative Commons Attribution 4.0 International License (CCBY-NC-SA-4.0). View this license's legal deed at https://creativecommons.org/licenses/by-nc-sa/4.0 and legal code at https://creativecommons.org/licenses/by-nc-sa/4.0/legalcode for more information. 


\section{REFERENCES}

1. Conte S, Camp CL, Dines JS. Injury trends in Major League Baseball over 18 seasons: 1998-2015. Am J Orthop. 2016;45(3):116-123.

2. Dick R, Sauers EL, Agel J, et al. Descriptive epidemiology of collegiate men's baseball injuries: National Collegiate Athletic Association injury surveillance system, 1988-1989 through 2003-2004. J Athl Train. 2007;42(2):183-193.

3. Trakis JE, McHugh MP, Caracciolo PA, Busciacco L, Mullaney M, Nicholas SJ. Muscle strength and range of motion in adolescent pitchers with throwingrelated pain: Implications for injury prevention. Am J Sports Med. 2008;36(11):2173-2178. doi:10.1177/0363 $\underline{546508319049}$

4. Byram IR, Bushnell BD, Dugger K, Charron K, Harrell FE Jr, Noonan TJ. Preseason shoulder strength measurements in professional baseball pitchers: identifying players at risk for injury. Am J Sports Med. 2010;38(7):1375-1382. doi:10.1177/036354650936040 $\underline{4}$

5. Wasserberger KW, Barfield JW, Downs JL, Oliver GD. Glenohumeral external rotation weakness partially accounts for increased humeral rotation torque in youth baseball pitchers. J Sci Med Sport. 2020;23(4):361-365.

6. Agresta CE, Krieg K, Freehill MT. Risk factors for baseball-related arm injuries: A systematic review. Orthop J Sports Med. 2019;7(2):2325967119825557. do $\mathrm{i}: 10.1177 / 2325967119825557$

7. Dodds FT, Knotts A-LS, Penrod MI, Scoggins WA, Conners RT. Shoulder strength and range of motion between colegiate pitchers and position players in baseball. Int J Exerc Sci. 2020;13(6):123-130.

8. Donatelli R, Ellenbecker TS, Ekedahl SR, Wilkes JS, Kocher K, Adam J. Assessment of shoulder strength in professional baseball pitchers. J Orthop Sports Phys Ther. 2000;30(9):544-551.

9. Ellenbecker TS, Mattalino AJ. Concentric isokinetic shoulder internal and external rotation strength in professional baseball pitchers. J Orthop Sports Phys Ther. 1997;25(5):323-328.

10. Bullock GS, Chapman T, Joyce T, Prengle R, Stern $\mathrm{T}$, Butler RJ. Examining differences in movement competency in professional baseball players born in the United States and Dominican Republic. J Sport Rehabil. 2018;27(5):397-402. doi:10.1123/jsr2016-025 1
11. Axe MJ, Strube M, Osinski D, Andrews JR, SnyderMackler L. A speed distance-based classification system for injury prevention and research in international and domestic youth baseball players. Int J Sports Phys Ther. 2014;9(3):346-355.

12. Matsuura T, Suzue N, Kashiwaguchi S, Arisawa K, Yasui N. Elbow injuries in youth baseball players without prior elbow pain: A 1-year prospective study. Orthop J Sports Med. 2013;1(5). doi:10.1177/23259671 13509948

13. Otoshi K, Kikuchi S, Kato K, et al. Sufficient duration of off-season decreases elbow disorders in elementary school-aged baseball players. J Shoulder Elbow Surg. 2019;28:1098-1103.

14. Bullock GS, Faherty MS, Ledbetter L, Thigpen CA, Sell TC. Shoulder range of motion and with baseball arm injuries: A systematic review and meta-analysis. J Athl Train. 2018;53(12):1190-1199. doi:10.4085/106 $\underline{2-6050-439-17}$

15. Thomas SJ, Sheridan S, Reuther KE. Humeral retroversion and participation age in professional baseball pitchers by geographic region. J Athl Train. 2020;55(1):27-31.

16. Hurd WJ, Kaplan KM, ElAttrache NS, Jobe FW, Morrey BF, Kaufman KR. A profile of glenohumeral internal and external rotation motion in the uninjured high school baseball pitcher, part II: strength. J Athl Train. 2011;46(3):289-295.

17. Wilk KE, Meister K, Andrews JR. Current concepts in rehabilitation of the overhead throwing athlete. Am J Sports Med. 2002;30(1):136-151.

18. Garrison C. Baseball players with ulnar collateral ligament tears demonstrate decreased rotator cuff strength compared to healthy controls. Int J Sports Phys Ther. 2015;10(4):476-481.

19. Moreno-Pérez V, Elvira JLL, Fernandez-Fernandez J, Vera-Garcia FJ. A comparative study of passive shoulder rotation range of motion, isometric rotation strength and serve speed between elite tennis players with and without history of shoulder pain. Int J Sports Phys Ther. 2018;13(1):39-49. doi:10.26603/ijspt20180 $\underline{039}$

20. Dugas JR, Looze CA, Capogna B, et al. Ulnar collateral ligament repair with collagen-dipped FiberTape augmentation in overhead-throwing athletes. Am J Sports Med. 2019;47(5):1096-1102. do i:10.1177/0363546519833684 